\title{
Protocolo de atención a un paciente con diagnóstico de pulpitis irreversible
}

Protocol of care in a patient diagnosed with
irreversible pulpitis

Fecha de Recepción

16 de diciembre de 2015
Protocolo de cuidados em um paciente diagnosticado com pulpite irreversível
Montiel Natalia Belen

Alves Laura Patricia

Arias Gorman Liliana

Galiana Mariel

Lugo de Langhe Carlos Daniel

Gualdoni Graciela
Aceptado para su publicación

04 de mayo de 2016

\section{Resumen}

El tratamiento endodóntico implica la eliminación del tejido pulpar afectado por procesos inflamatorios producidos por causas bacterianas, físicas y/o químicas que llevan a su remoción total para conservar el órgano dental como parte funcional del sistema estomatognático. La biopulpectomía es un procedimiento endodóntico que se realiza en casos de pulpas vitales con procesos inflamatorios irreversibles. Implica la eliminación, limpieza y conformación de la cavidad pulpar creando un ambiente óptimo para la obturación tridimensional del sistema de conductos radiculares. En este artículo se brinda un protocolo de atención a pacientes con diagnóstico de pulpitis irreversibles que concurren a la cátedra de endodoncia de $5^{\circ}$ año de la facultad de Odontología de la UNNE.

\section{Palabras claves}

Cavidad pulpar, tratamiento endodóntico, extirpación pulpar, endodoncia.

\section{Summary}

Endodontic treatment involves the removal of the pulp tissue affected by inflammatory processes caused by bacterial, physical and / or chemical causes leading to their total removal to preserve the dental organ as a functional part of the stomatognathic system. The endodontic biopulpectomia is a procedure performed in cases of vital pulps with irreversible 
inflammatory processes. It involves the removal, cleaning and conformation of the pulp cavity creating an optimal environment for three-dimensional sealing of the root canal system. In this article a protocol of care provided to patients diagnosed with irreversible pulpitis which contribute to the Chair of Endodontics of 5 th year of the Faculty of Dentistry UNNE.

\section{Key words}

Pulp cavity, endodontic treatment, pulp removal, endodontics.

\section{Resumo}

Endodôntico tratamento envolve a remoção do tecido pulpar afectadas por processos inflamatórios provocados por causas bacterianas, físicas e/ou químicas que levam à sua remoção total para preservar o órgão dental como uma parte funcional do sistema estomatognático. O biopulpectomia endodôntico é um procedimento realizado nos casos de polpas vitais com processos inflamatórios irreversíveis. Envolve a remoção, limpeza e conformação da cavidade pulpar criando um ambiente ideal para a selagem tridimensional do sistema de canal radicular. Neste artigo um protocolo de atendimento a pacientes diagnosticados com pulpite irreversível que contribuem para a Cátedra de Endodontia do $5^{\circ}$ ano da Faculdade de Odontologia UNNE.

\section{Palavras chaves}

Cavidade pulpar, tratamento endodôntico, retirada da polpa, endodontia.

\section{Introducción}

Endodoncia es la ciencia que se ocupa de la etiología prevención, diagnóstico y tratamiento de las alteraciones patológicas de la pulpa dental' y sus repercusiones en la región apical y periapical, y por consiguiente en todo el organismo ${ }^{2}$. El tratamiento endodóntico implica el estudio, diagnóstico, prevención y tratamiento de todas las causas que afectan al tejido pulpar y sus tejidos perriradiculares.

La preparación del conducto radicular implica un conjunto de procedimientos mecánicos y químicos que tienen por finalidad limpiar y conformar y (en los casos de dientes con pulpa mortificada) desinfectar el conducto creando las condiciones óptimas para obturarse ${ }^{3}$.

En la actualidad existe una alta demanda de pacientes que requieren tratamiento endodóntico con la finalidad de preservar el órgano dental y que este continúe en la arcada dentaria cumpliendo su rol funcional.

Ha sido postulado que un correcto tratamiento endodóntico está basado en una tríada de factores que se relacionan entre sí y que incluyen el acceso, la preparación y la obturación radicular .Estos factores no son suficientes para lograr el éxito, pues deben ser complementados por la irrigación, la medicación intraconducto, cuando el caso lo requiera y un buen sellado coronario temporal y definitivo mediante una adecuada rehabilitación de la pieza dentaria con la finalidad de restituir su función ${ }^{4}$.

Los tratamientos endodónticos son dos: Biopulpectomía y tratamiento endodóntico. El tratamiento de biopulpectomía se realiza en los casos en los que el tejido pulpar se encuentra vital pero debe removerse por estar afectado en forma irreversible por un proceso inflamatorio inducido por la acción de bacterias, agentes físicos o químicos que lo dañan de manera tal que se requiere de su remoción total.

En la clínica de endodoncia de la facultad de odontología concurren pacientes de distintas edades que requieren de atención odontológica y que son atendidos por los alumnos de 5 to año de la facultad. Es de importancia brindar a través de este artículo información de la metodología de trabajo del alumno de grado, 5to. año que concurre a la cátedra de endodoncia de la facultad de odontología de la UNNE.

\section{Caso clínico}

Se presenta a la consulta un paciente de sexo masculino, de 16 años de edad, con la presencia de una pieza dentaria con caries extensa en la superficie vestibular, mesial y palatino de un incisivo lateral superior, el motivo principal de la consulta fue la presencia de dolor dentario. El paciente manifestó que la pieza dentaria fue arreglada con anterioridad y que luego de unos meses el arreglo cayó y comenzaron las 
molestias al frío y calor, intensificándose aún más con el correr de los días.

Como primera medida se realiza la radiografía preoperatoria (figura I) y confección de la historia clínica obteniendo la información correspondiente a datos filiales, antecedentes médicos y la anamnesis de los signos y síntomas que presentó la paciente. Antes de comenzar el tratamiento se hace firmar al paciente $y$ al tutor el consentimiento informado.

Se procedió a realizar anestesia y aislamiento absoluto de la pieza dentaria. Se eliminó toda la caries y se realizó la apertura para acceso endodóntico. Se realizó cateterismo para explorar el conducto con una lima $\mathrm{KN}^{\circ} \mathrm{I}$, se extirpó el tejido pulpar y se cohibió la hemorragia con hipoclorito de sodio al 2,5\%. Se procedió a tomar la longitud de trabajo con el método radiográfico de Ingle (figura 2) y se realizó la preparación biomecánica conformando el tercio apical con limas manuales tipo $\mathrm{K}$, hasta la lima $\mathrm{N}^{\circ} 40$ y el tercio medio y coronario se limaron con limas $\mathrm{K}$ y $\mathrm{H}$ en forma alternada hasta la lima $\mathrm{N}^{\circ} 60$. Entre cada cambio de instrumento se irrigó con hipoclorito de sodio al 2,5\% para la eliminación de restos tisulares y barrillo dentinario. Terminada la conformación se secó el conducto con conos de papel y se tomó la radiografía de conometría (figura 3). Posteriormente se procedió a obturar el conducto radicular aplicando sellador en las paredes y con la técnica de compactación lateral se rellenó el interior del conducto con conos de gutapercha hasta conseguir una obturación completa del mismo.

Finalmente se limpió la cámara pulpar con una torunda de algodón y alcohol y se sello de manera temporaria con cavit e ionómero vítreo realizándose la radiografía posoperatoria. Se advirtió al paciente la necesidad de realizarse la restauración definitiva en forma inmediata para evitar la microfiltración bacteriana y como consecuencia el fracaso endodóntico.

\section{Discusión}

En el tratamiento endodóntico de biopulpectomia la pulpa dental se encuentra viva pero debe ser removida por estar afectada por un proceso inflamatorio que la daña de manera irreversible ${ }^{3}$. Los microorganismos en general se encuentran confinados en la porción más superficial del tejido pulpar, sin contaminar la pulpa radicular por lo que la preparación radicular en estor casos busca la remoción del tejido orgánico y la creación de condiciones morfológicas y dimensionales para que se pueda proceder a una obturación correcta ${ }^{3}$. Es por ello que para establecer una correcta indicación del tratamiento es de suma importancia establecer un adecuado diagnostico clínico y radiográfico de la alteración patológica pulpar aguda correlacionando los datos semiológicos y radiográficos ${ }^{2}$ obtenidos de la historia clínica realizada al paciente.

Si bien los casos de biopulpectomias pueden llevarse a cabo en una única sesión operatoria, existen casos en los que no puede concluirse el tratamiento en una única sesión siendo imprescindible la colocación de una medicación intraconducto temporaria, la cual permanecerá en el interior del conducto hasta la siguiente sesión.

Por lo tanto debemos encaminar el tratamiento endodóntico hacia la completa reparación o regeneración periapical, mediante la eliminación del mayor número de factores que propician y mantienen estos estados inflamatorios procurando un buen desbridamiento del o los conductos radiculares, una correcta irrigación, tratando que la medicación intraconducto, cuando fuese necesaria, cree un ambiente favorable para la reparación periapical y una obturación radicular del conducto instrumentado que evite la filtración de los elementos periapicales al interior del mismo 4 .

El sellado coronario es un factor que influye en la contaminación y/o recontaminación de un conducto radicular. Lamentablemente todos los materiales de obturación temporaria filtran y la falta de una restauración definitiva conlleva al fracaso del tratamiento endodóntico ${ }^{4}$. Por todos estos motivos es importante la rehabilitación postendodóntica adecuada de la pieza lo más pronto posible. El profesional debe concientizar al paciente sobre la necesidad de efectuarse la restauración definitiva lo antes posible, pues es parte del tratamiento y no sólo la desaparición de los síntomas dolorosos.

Para lograr el éxito en una endodoncia es necesaria la conjugación del tratamiento endodóntico-restaurador. En algunos casos se ha podido observar el fracaso del tratamiento endodóntico 


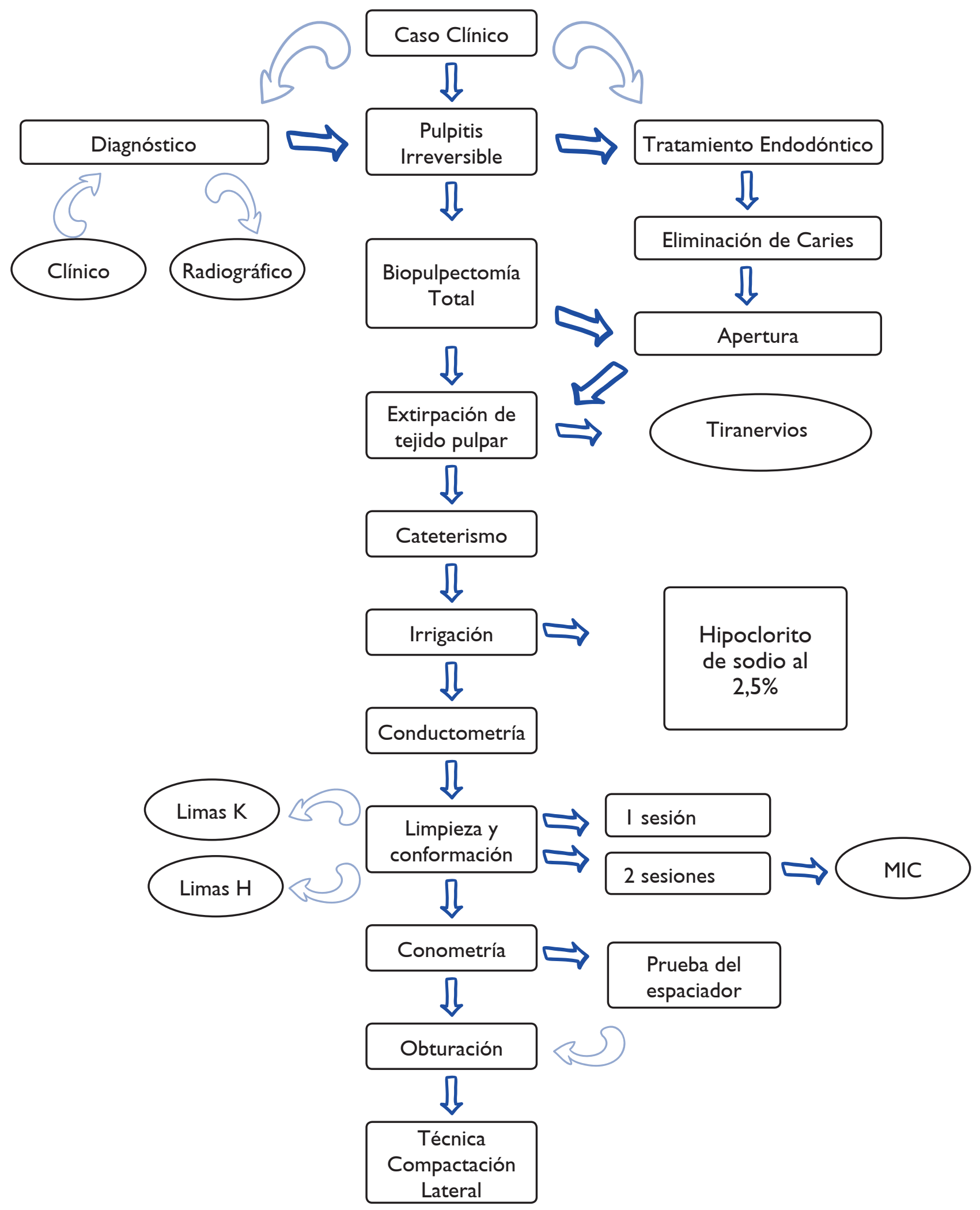




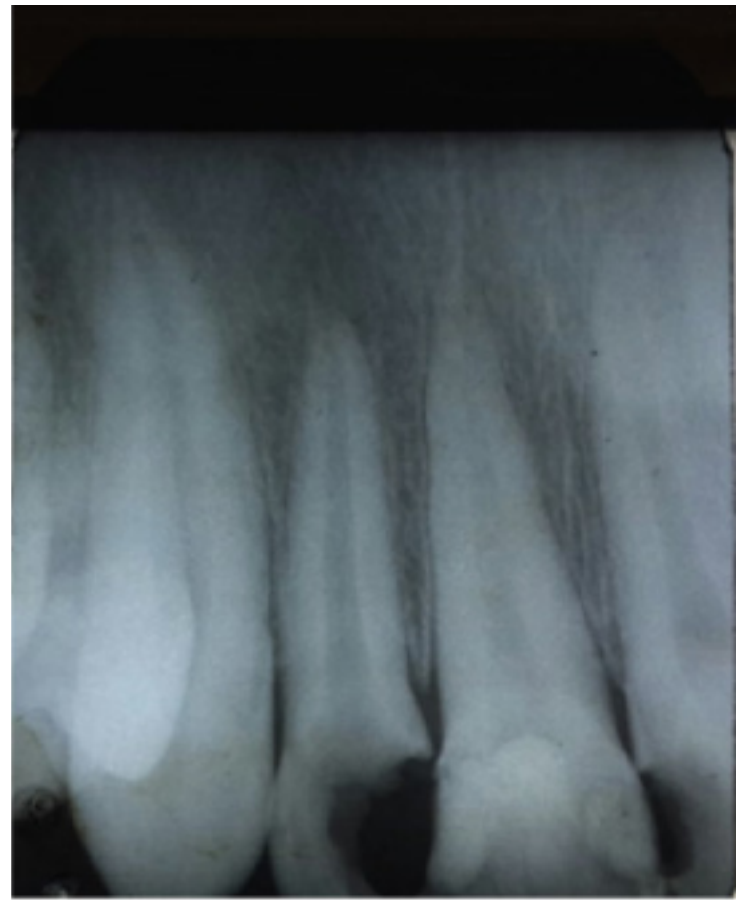

Figura I. Rx Preoperatoria P.D I2.

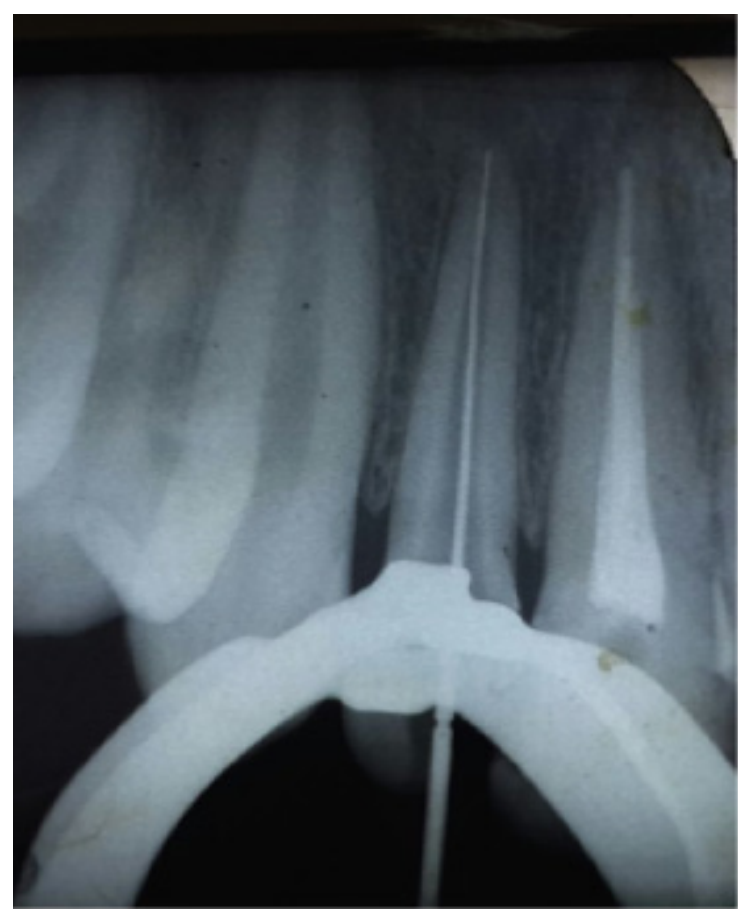

Figura 3. Rx de Conometría.

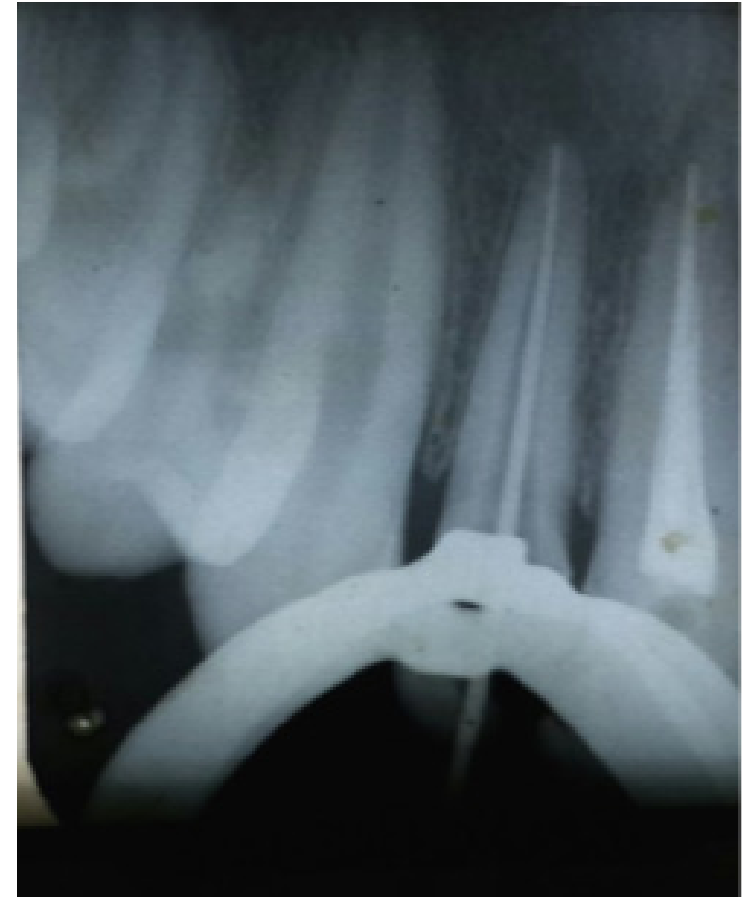

Figura 2. Rx de Conductometría P.D I2.

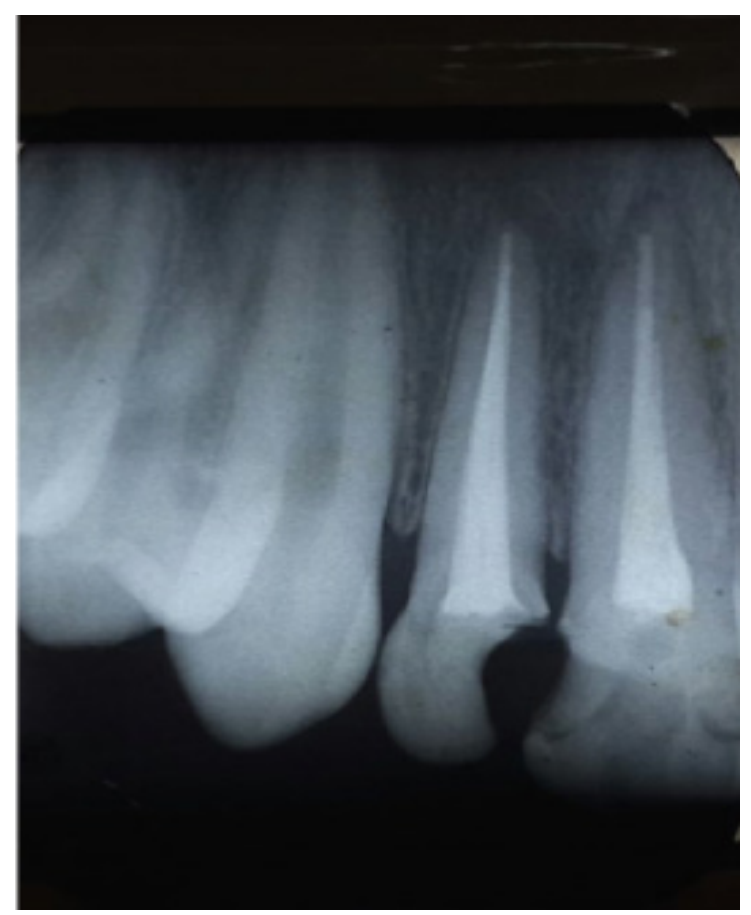

Figura 4. Rx posoperatoria. 
REVISTA FACULTAD DE ODONTOLOGÍA

ISSN No 1668-7280 - Vol. IX No 1 - 2016
CASO CLINICO

Montiel - Alves - Arias Gorman - Galiana - Lugo de Langhe - Gualdoni por la no culminación del tratamiento restaurador, descuidando el factor funcional y estético y contribuyendo a una microfiltración bacteriana por la falta de sellado hermético incumpliendo el protocolo de un tratamiento integral adecuado. Además la falta de cooperación o descuido por parte del paciente, como la carencia de información por parte del profesional hacia el paciente ${ }^{6}$ hace que en muchas ocasiones se descuide la restauración definitiva. Es por ello que tanto el alumno como el profesional que atiende al paciente deben hacer énfasis en la importancia de la misma para que se logre la restitución funcional completa de la pieza dentaria.

No obstante el éxito del tratamiento endodóntico no depende únicamente de un buen sellado coronario pero contribuye en parte al no fracaso, ya que los dientes endodonciados requieren indudablemente un tipo restauración más allá de una simple obturación debido a su grado de destrucción ${ }^{6}$. Esto quiere decir, que la efectividad del tratamiento depende de la interrelación tanto del tratamiento endodóntico como el restaurador ${ }^{7}$.

\section{Conclusión}

En el siguiente trabajo presentado se abordó la atención de un paciente que concurrió con dolor dentario realizando una serie de pasos protocolares que llevan a la culminación de un tratamiento endodóntico (figura $\mathrm{N}^{\circ}$ 5). Cabe aclarar que en este caso la intervención endodóntica se llevo a cabo en una única sesión operatoria. En caso de requerir de más sesiones para la culminación del tratamiento es aconsejable la colocación de una medicación intraconducto (MIC).

\section{Bibliografía}

I Stephen Cohen, Richad C. Burns. Endodoncia. Los caminos de la pulpa. Quinta Edición. México:Editorial panamericana; 1995. Pág. 92-134

2 Leonardo MR. Endodoncia. Tratamiento de Conductos Radiculares. Principios técnicos y Biológicos. Volumen I. San Pablo Brasil: Editorial Artes Médicas Latinoamericana. Pág 87-109

3 Soares IJ, Goldberg F. Endodoncia. Técnica y fundamentos. Iera. Edición, 3era reimpresión. Buenos Aires. Argentina: Editorial Medica Panamericana; 2007. Pág 76-10I

4 Hilu R.- Balandrano Pinal F. El éxito en endodoncia. Endodoncia 2009; 27 (3):131-138. Disponible en http://www.medlinedental.com/pdfdoc/endo/v27-3-7.pdf.

5 Alvarez Rodríguez Javier, Clavera Vázquez Teresita de Jesús, Becerra Alonso Odalys, Rodriguez Ledesma Ernesto Boris. Tratamiento endodóntico radical en pulpa no vital en una sola visita. Rev haban cienc méd [revista en la Internet]. 2014 Abr [citado 2015 Nov 03]; 13 (2): 219 226. Disponible en: http://scielo.sld.cu/scielo. php?script=sci_arttext\&pid=SI $7295 \mid$ I $X 201400$ 0200007\&lng=es

6 Nieto Cisneros AR "Efectividad del tratamiento endodóntico-restaurador en la rehabilitación funcional y estética en piezas unirradiculares". Guayaquil, 2014. Disponible en: http://repositorio.ug.edu.ec/bitstream/redug/6267/I/NIETOanny.pdf

7 Puente, S. Éxito y fracaso en el tratamiento de endodoncia. Lima-Perú 2008. Disponible en: http://www.cop.org.pe/bib/investigacionbibliografica/SUSYDELCARMENPUENTESAAVEDRA.pdf

8 Mondragón Espinoza Jaime. Endodoncia. México: Editorial Interamericana MC graww; 1995. Pág109-122.

9 Weine Franklin S. Tratamiento endodóntico. Quinta edición. Madrid España: Editorial Harcourt Brace; 1997. 